\title{
Within-microenvironment exposure to particulate matter and health effects in children with asthma: a pilot study utilizing real-time personal monitoring with GPS interface
}

Nathan Rabinovitch ${ }^{1}$, Colby D. Adams², Matthew Strand ${ }^{3}$, Kirsten Koehler ${ }^{4}$ and John Volckens ${ }^{2,5^{*}}$ (D)

\begin{abstract}
Background: Most particulate matter (PM) and health studies in children with asthma use exposures averaged over the course of a day and do not take into account spatial/temporal variability that presumably occurs as children move from home, into transit and then school microenvironments. The objectives of this work were to identify increases in morning PM exposure occurring within home, transit and school microenvironments and determine their associations with asthma-related inflammation and rescue medication use.

Methods: In 2007-2008, thirty Denver-area schoolchildren with asthma performed personal PM exposure monitoring using a real-time sensor integrated with a geographic information system (GIS) to apportion exposures to home, transit and school microenvironments. Concurrently, daily monitoring of the airway inflammatory biomarker urinary leukotriene E4 (uLTE 4 ) and albuterol usage was performed.

Results: Mean PM exposures each morning were relatively well correlated between microenvironments for subject samples $(0.3<r<0.8)$, thus limiting use of this exposure metric to attribute health effects to PM exposure in specific microenvironments. Within-microenvironment increases in exposure, such as would be characterized by one or a series of transient spikes or a sustained increase in concentration (exposure event), however, were not strongly correlated between microenvironments $(|r|<0.25)$. On days when children were exposed to a $\geq 5 \mu \mathrm{g} / \mathrm{m}^{3}$ exposure event during transit, they demonstrated a $24.0 \%$ increase in $\mathrm{uLTE}_{4}(95 \% \mathrm{Cl}: 1.5 \%, 51.5 \%)$ and a $9.7 \%(-5.9 \%, 27.9 \%)$ increase in albuterol usage compared to days without transit exposure events. Associations between exposure events and health outcomes in home and school microenvironments tended to be positive as well, but weaker than for transit.
\end{abstract}

Conclusions: School children with asthma moving across morning microenvironments experience spatially heterogeneous PM exposures with potentially varying health effects.

Keywords: Spatio-temporal, Aerosol, Air pollution, Inflammation, Epidemiology

\footnotetext{
*Correspondence: john.volckens@colostate.edu

${ }^{2}$ Department of Environmental and Radiological Health Sciences, Colorado

State University, Fort Collins, CO, USA

${ }^{5}$ Department of Mechanical Engineering, Colorado State University, 1374

Campus Delivery, Fort Collins, CO 80523, USA

Full list of author information is available at the end of the article
} 


\section{Background}

Time-series studies have reported associations between ambient air pollution concentrations and acute asthma exacerbations in adults and children with asthma [1]. These studies often utilize fixed-site monitors that measure ambient particulate matter (PM) thought to be primarily products of combustion from energy consumption and transportation sources in the urban setting. However, these fixed-site monitors are unable to fully capture the spatial and temporal heterogeneity of an individual's personal exposure due to a combination of personal behaviors and microenvironmental sources. As a result, individual exposure estimates derived from ambient monitoring data are subject to measurement error [2, 3]. Few studies have assessed asthma health effects in highly mobile populations (such as children) as a function of exposure by microenvironment.

To determine the potential role of differing microenvironments on PM exposures and their effects on asthma, the present study utilized a novel personal monitoring system that integrated a real-time sensor package with a geographic information system (GIS) [4] to apportion exposures to the home, transit and school microenvironments. This approach allowed for identification of spatially and temporally heterogeneous PM exposures that may vary by microenvironment. We characterized these microenvironmental exposures using both traditional (mean, maximum) and novel (increase, exposure event) exposure metrics. We then determined if these exposure metrics were associated with increases in airway inflammation as measured by the biomarker urinary leukotriene E4 ( $\mathrm{uLTE}_{4}$ ) and with as-needed albuterol usage in schoolchildren with asthma.

\section{Methods}

\section{Study subjects}

Thirty elementary schoolchildren with physician-diagnosed asthma, who attended the Kunsberg (now Morgridge) School at National Jewish Health (NJH, Denver, CO), were studied over a 5-month period (December 2007- April 2008). Ethical and scientific approval was obtained from the NJH Institutional Review Board.

\section{Personal PM exposures by microenvironment}

Personal PM exposures were measured continuously on a daily basis using a recently developed method for personal, spatiotemporal exposure assessment (see [4] and on line-supplement for methodology). Each child's air pollution exposure was monitored for up to 4 consecutive school days (mid-day Monday through mid-day Friday) across two non-consecutive weeks (8 days total). Predetermined microenvironment classifications (at home, during transit to/from school, and at school) were made with time-, location-, and sensor-based algorithms (Fig. 1; see [4] and on-line supplement for methodology).

Subjects wore sampling backpacks containing an aerosol nephelometer to measure fine PM concentrations, a global positioning system (GPS) receiver (GPSMap $60 \mathrm{Cx}$, Garmin Inc. Olathe KS) to record geographic position data, and a temperature sensor to record ambient temperature (see Additional file 1: Figure S1). Each monitor recorded data at 10-s intervals. Personal PM levels were actively sampled with a Personal DataRAM 1200, or pDR, (Thermo Fisher Scientific Inc., Waltham, $\mathrm{MA})$ in conjunction with a pump $(6.8 \mathrm{~L} / \mathrm{min}$ flow, Omni Personal Pump, BGI Inc., Waltham MA) and cyclone (1.5 $\mu \mathrm{m}$ size cut, Model GK2.05, BGI Inc., Waltham MA). The $1.5 \mu \mathrm{m}$ aerodynamic size cut resulted from the volumetric flow necessary to meet method quantification limits for gravimetric analysis of a filter sampler (Teflo 37mm, Pall Inc. East Hills, NY) located immediately downstream of the pDR. The pDR has been used extensively to assess personal PM exposure [5-7] and has been found to be precise and in good agreement with other continuous monitors [8]. To correct for instrument bias due to PM light scattering properties, data from the $\mathrm{pDR}$ were normalized to mass on the corresponding personal filter [9] during data processing. The normalization factor was calculated from the ratio of the average, daily personal filter gravimetric measurement to the corresponding $\mathrm{pDR}$ average; this correction was specific to each child's daily exposure. Daily meteorology measurements (temperature, relative humidity, barometric pressure) used in analyses were obtained from the Colorado Department of Public Health and Environment.

The microenvironment classification algorithm has been described in detail previously [4]. Briefly, geographical areas, or buffer regions, were developed to define an area surrounding the location of each child's home and the school using geographical information system software (ArcGIS 9.1, ESRI Inc.). The size and shape of the buffer regions were optimized to minimize misclassification error, especially during times of transit between home and school. Using the customized home and school buffer regions in conjunction with time-based rules, a spatiotemporal algorithm was applied to apportion exposure time series into pre-determined microenvironments: at home, at school, and morning transit (i.e., commuting from home to school). Accuracy of the classification for home and school using this method during a pilot study were greater than $98 \%$ [4]. Additional quality assurance of the processed data was performed to ensure that the child was carrying the backpack during the sampling period. Conditions for eliminating the daily sample data included when geospatial information indicated the backpack was left at school overnight, or if the backpack was left in a car overnight (as determined from temperature data). 


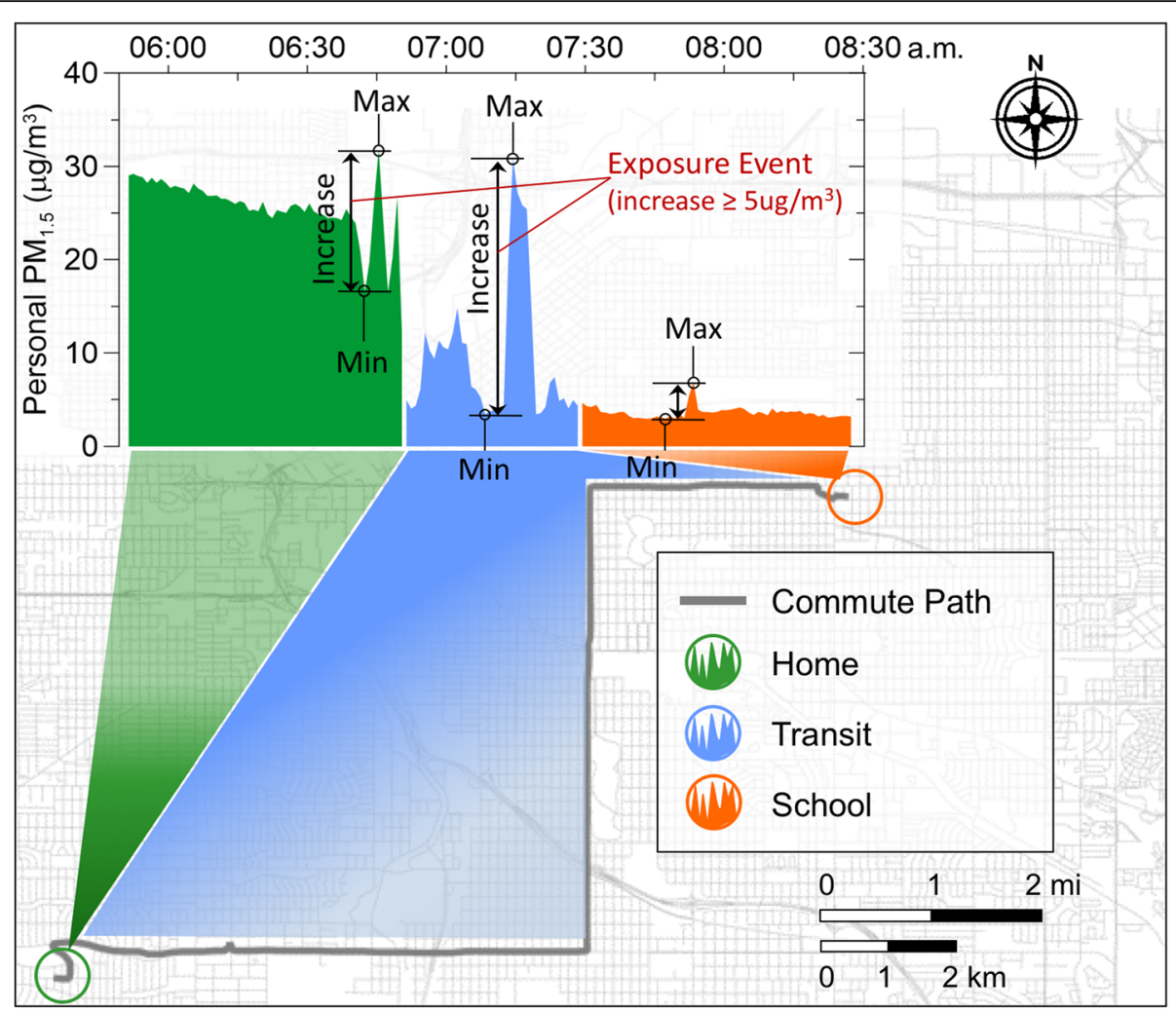

Fig. 1 Example profile of one child's personal exposure to PM 1.5 across a morning commute from home to school in Denver, CO. Exposure and time-location data are collected on children in real-time and apportioned into distinct microenvironments: at home, in transit, and at school. Also shown are three observations of the increase variable, as they would be calculated for each microenvironment

\section{Health outcome measurements}

An electronic monitor (Doser) recorded school-time albuterol use as the total number of activations in a $24-\mathrm{h}$ period. Urine was collected between 8:00 a.m. and 11:30 a.m. (80 \% between 9:30 a.m. and 10:30 a.m.) on school days (Monday - Friday). Samples were batch assayed for $\mathrm{uLTE}_{4}$, cotinine (a marker of environmental tobacco smoke exposure), and creatinine (to normalize levels for urinary volume) levels as previously described [10]. Daily surveys included questions determining presence or absence of upper respiratory infection (URI) symptoms and mode of transit (e.g. car, bus, van, walk to school).

\section{Pollution exposure concentration variables}

For purposes of the health effect analysis, personal PM exposure variables were defined for the following microenvironment times: one hour before commuting to school (home), time spent commuting to school (transit), and the first hour spent within the school (school). Traditional variables used in our exposure analyses were the mean and maximum, defined as: mean = concentration averaged over all measurements within a given microenvironment time; 1 -minute maximum = the maximum value of 1 -min averaged concentration readings within the microenvironment time. Both mean and 1-min maximum concentration variables were computed and analyzed on the natural log scale. We also constructed novel exposure variables ("increase" and "exposure event") specifically to reduce correlation between measurements in adjacent microenvironments. We defined increase as the maximum concentration in the current microenvironment time minus the minimum concentration among observations that preceded the maximum, starting with the last observation in the previous microenvironment time; and exposure event as a binary indicator of whether the increase exceeded 5 or $10 \mu \mathrm{g} / \mathrm{m}^{3}$. Minimum and maximum concentrations used to calculate increase were determined based on geometric means of 1-min data (i.e., 1-min average of logged concentrations, exponentiated). Examples of increase and exposure event variables are illustrated in Fig. 1; exposure profiles for all 125 monitoring days are included in the Additional file 1 .

\section{Statistical analyses}

Health outcomes were modeled as a function of personal PM concentration variables using linear mixed models (for $\mathrm{uLTE}_{4}$ ) or generalized linear models employing generalized estimating equations (for albuterol usage counts). Daily within-subject serial correlation was modeled using a spatial power structure in the linear mixed 
models and a working first-order autoregressive structure in the generalized linear models. For the latter, intermittent daily measurements were accounted for by including 'missing records', as necessary. The linear mixed models also included random intercepts for subjects to account for general differences in uLTE $_{4}$ levels between subjects. For albuterol models, the log link was used - i.e., Poisson regression, and for uLTE $_{4}$ models, the outcome was logged before analysis; thus, exponentiated slope estimates from these models have relative change interpretations (after subtracting 1). For more detail, see the Additional file 1.

Based on results from our previous studies [11, 12], only the same-day and 1-day lag between pollutant and health outcome were examined (plus the 2-day average or composite). Covariates in models included upper-respiratory infection (URI) indicator for $\mathrm{uLTE}_{4}$, a non-exercise day indicator for albuterol (distinguishing exercise and nonexercise days at school), and ambient temperature in both models; other meteorological variables were tested but dropped due to insignificance. Reported p-values are based on 2-sided tests. Effect estimates were standardized by interquartile range (i.e. 75 th percentile minus the 25 th percentile for the pollutant), except for the exposure event dichotomized variables. All statistical analyses were conducted using SAS, PROC MIXED (version 9.4).

\section{Results}

Table 1 contains a summary of the demographics and physiological characteristics of the panel. Children were predominately African American (43\%), followed by

Table 1 Demographics, asthma severity, and albuterol and $\mathrm{uLTE}_{4}$ levels

\begin{tabular}{|c|c|}
\hline Subject variable & Data \\
\hline Panel size & 30 \\
\hline Mild asthma ${ }^{a}$ & 11 (36.7 \%) \\
\hline Moderate asthma ${ }^{a}$ & 13 (43.3 \%) \\
\hline Severe asthma ${ }^{a}$ & $6(20.0 \%)$ \\
\hline African American & $13(43.3 \%)$ \\
\hline Children with at least one ICU admission for asthma & 10 (33.3 \%) \\
\hline $\begin{array}{l}\text { Children with at least one exacerbation } \\
\text { within the past year }^{\text {b }}\end{array}$ & 19 (63.3\%) \\
\hline Children using daily inhaled steroids & $26(86.7 \%)$ \\
\hline Urinary $\mathrm{LTE}_{4}$ (pg per mg creatinine) & $87.44(5.3,839)$ \\
\hline Albuterol (puffs per day) & $1.40(0,3)$ \\
\hline Age & $10(7,13)$ \\
\hline
\end{tabular}

Definition of abbreviation: ICU - intensive care unit

Entries are number (percentage) of children or mean (minimum, maximum) unless otherwise indicated

${ }^{\mathrm{a}}$ Daily asthma severity categories were defined by National Asthma Education and Prevention Program criteria (reference 13)

${ }^{b}$ Exacerbations were defined as episodes requiring hospitalization, visits to emergency or urgent care departments, or prednisone bursts multiracial (36 \%), Hispanic (16\%) and White (5\%). Onethird had been admitted into an intensive care unit for asthma at least once in their lifetime and over $60 \%$ had experienced an asthma exacerbation requiring a prednisone burst during the previous year. Based on the frequency of nighttime symptoms, most subjects were classified as having moderate asthma by National Asthma Education and Prevention Program guidelines [13].

Tables 2 and 3 and Additional file 1: Table S1 summarize personal $\mathrm{PM}_{1.5}$ concentrations measured at home, transit and school microenvironments (for varying time scales during the morning interval) and for approximately $21 \mathrm{~h}$ (2:30 pm to 11:30 am) averaged concentrations (as monitors were processed and batteries replaced over a 3-h period at school). Personal exposures tended to be highest at home and lowest at school. Transit to school for most (84 \%) children occurred by motor vehicle (bus, $3 \%$; vanpool $64 \%$; or car, $17 \%$ ) while $16 \%$ of children walked to school. The majority of vehicular routes were on major city streets with traffic flow managed by stoplights. Transit to school typically began at approximately 7:00 a.m. lasting 32 $\mathrm{min}$, on average (standard deviation $=15$, range 9-85 $\mathrm{min}$ ).

Figure 1 illustrates an example of one child's microenvironmental exposure profile. In this example, the transit and home microenvironments contain an exposure event (i.e. an increase of at least $5 \mathrm{ug} / \mathrm{m}^{3}$ ) but the school microenvironment does not (all profiles are included in the Additional file 1: Figure S4). Using these parameters, exposure events of at least $5 \mu \mathrm{g} / \mathrm{m}^{3}$ were detected in $56 \%$ $(n=71)$ of home, $50 \%(n=63)$ of transit and $41 \%$ $(n=51)$ of school profiles.

Table 4 summarizes Pearson correlations between and within microenvironments for the different exposure metrics. Mean values for personal microenvironmental exposure were correlated especially well between transit and school $(r=0.77)$; less so between home/transit $(r=0.42)$ and home/school $(r=0.33)$. In contrast to mean exposures, exposure increases in one microenvironment were only weakly correlated with increases in subsequent microenvironments $(r=0.24$ for home/transit, $r=0.13$ for transit/school, $r=-0.09$ for home/school). Mean PM exposures were moderately correlated with increases in the same microenvironment $(r=0.59$ for home, $r=0.58$ for transit, $r=0.42$ for school).

Comparisons among model goodness-of-fit statistics (using Akaike Information Criterion [AIC] for $\mathrm{LTE}_{4}$ and Quasi-likelihood under the independence model criterion $\mathrm{u}[\mathrm{QICu}]$ for albuterol use) associating increase, event, mean, and max exposure metrics with health effects are provided in Additional file 1: Table S3. These goodness of fit models demonstrate that in general metrics using the event variables fit the data better than either the mean or 1-min max variables and that utilizing the increase as a continuous variable generally did 
Table 2 Average $\mathrm{PM}_{1.5}$ concentrations by micronenvironment, $\mu \mathrm{g} / \mathrm{m}^{3 \mathrm{a}}$

\begin{tabular}{|c|c|c|c|c|c|c|}
\hline Microenvironment or time frame & Mean & Min value & 25th quantile & Median & 75th quantile & Max value \\
\hline Home & 12.7 & 0.2 & 2.5 & 5.2 & 14.3 & 109.5 \\
\hline Transit & 9.2 & 0.1 & 2.4 & 5.3 & 12.2 & 61.6 \\
\hline School & 6.4 & 0.1 & 1.9 & 3.7 & 8.1 & 44.9 \\
\hline Complete sample ${ }^{b}$ & 9.5 & 0.1 & 2.2 & 4.7 & 11.8 & 109.5 \\
\hline
\end{tabular}

${ }^{a}$ Statistics were computed at the subject-day level, not distinguishing between versus within-subject data. Statistics were computed by first determining means within samples (subject, day and microenvironment), then computing statistics across the 125 samples. $\mathrm{PM}_{1.5}$ is particulate matter less than $1.5 \mu \mathrm{m}$ in aerodynamic diameter. Home, Transit and School microenvironment times are summarized in the text

${ }^{b}$ Approximately 2:30pm through 11:30am the following day

not provide additional information in predicting health outcomes beyond the 5 or $10 \mu \mathrm{g} / \mathrm{m}^{3}$ exposure event variables. These results and the fact that increase and exposure event variables were less correlated between microenvironments, suggest that the event variable is the more informative metric for this study design than the more commonly used mean and max variables. In this particular dataset, we would consider the $5 \mu \mathrm{g} / \mathrm{m}^{3}$ cut-off as providing the most informative associations with health as it provided the best fit most often among all metrics.

Health effect estimates for $5 \mu \mathrm{g} / \mathrm{m}^{3}$ exposure events occurring on the same day (lag 0 ), previous day (lag 1 ), or on either day (0-1) are illustrated for $\mathrm{uLTE}_{4}$ and albuterol usage in Figs. 2 and 3, respectively, and summarized in Table 5. In health outcome models, a $5 \mu \mathrm{g} / \mathrm{m}^{3}$ exposure event in the transit microenvironment was associated with a $24.0 \%$ increase in $\mathrm{uLTE}_{4}(1.5 \%, 51.5 \%)$ and a $9.7 \%$ $(-5.9 \%, 27.9 \%)$ increase in albuterol usage on the same day. For the home and school microenvironments, estimates tended to also be positive, but somewhat weaker, as shown in Figs. 2 and 3. Lag 0, 1 and 2-day (i.e., 0-1) effect estimates based on exposure events of at least $10 \mu \mathrm{g} / \mathrm{m}^{3}$ yielded similar results, although not quite as pronounced as when using the $5 \mu \mathrm{g} / \mathrm{m}^{3}$ cut point (Table 5).

The microenvironment specific health-effect estimates could be confounded by the elapsed time between exposure and when the health outcome was measured, since school exposures were closest in time to outcome measurement, followed by transit, and then home exposures. Because we recorded daily urine collection times, we were able to examine this potential confounder by evaluating the timing of the relationship between personal PM exposures and $\mathrm{uLTE}_{4}$ measurement (i.e., urine collection). Specifically, $h r O$ was constructed as the mean $\log \mathrm{PM}_{1.5}$ concentration in the 60 min preceding urine collection, $h r 1$ was the mean log concentration for the 60 min ending $1 \mathrm{~h}$ before urine collection, and $h r 2$, ending $2 \mathrm{~h}$ before collection. The $h r 0$ to $h r 2$ variables were tested individually as predictors in the same-day $\mathrm{uLTE}_{4}$ models. Although effects generally did strengthen as time-to-measurement shortened, none of the hourly concentrations were significantly associated with $\mathrm{uLTE}_{4}$ levels ( $\mathrm{p}>0.2$ ). When adding $h r$ variables to models with exposure event indicators (i.e., co-pollutant models), the $h r$ variables remained insignificant and the exposure event indicators did not weaken and, in fact, increased slightly for associations with transit exposures. As previously mentioned, without an $h r$ variable, there was a 24.0 $\%$ increase in lag 0 uLTE $_{4}$ when there was one or more exposure events of at least $5 \mu \mathrm{g} / \mathrm{m}^{3}$ increase occurring in the transit microenvironment (95\% CI: 1.5, $51.5 \%$ ); when adding $h r$ variables, $\mathrm{uLTE}_{4}$ effect estimates $(95 \% \mathrm{CIs})$ with exposure events in transit were: $27.2 \%(3.6,56.3 \%)$ when $h r 0$ was added; $29.6 \%(5.5,59.2 \%)$ when $h r l$ was added and $30.3 \%(4.0,63.2 \%)$ when $h r 2$ was added to the models. Similarly, slight increases in estimates were also observed for the school microenvironment when adding $h r$ variables (from $10.6 \%$ without an $h r$ variable, up to $13.7 \%$ when adding $h r 1$ ), while estimates stayed approximately the same for the home microenvironment with the additions.

Health effect estimates using the mean metric for PM exposure are summarized in the Additional file 1: Table S2 and shown in Additional file 1: Figures S2 and S3. Similar to exposure events, mean PM concentrations during transit were marginally associated with both $\mathrm{uLTE}_{4}$ and albuterol usage, while associations for school and home exposures were somewhat weaker. Not surprisingly, health-effect associations with 1-min $\max$ concentrations yielded similar

Table 3 Statistics for within-sample $\mathrm{PM}_{1.5}$ increases (see text for formal definition of the 'increase' variable) ${ }^{\mathrm{a}}$

\begin{tabular}{lcccccccc}
\hline Microenvironment & Mean & Min value & 25th Quantile & Median & 75th Quantile & Max value & $\%$ at least $5 \mu \mathrm{g} / \mathrm{m}^{3}$ & $\%$ at least $10 \mu \mathrm{g} / \mathrm{m}^{3}$ \\
\hline Home & 24.0 & 0.0 & 1.6 & 7.4 & 19.4 & 282.1 & 56.8 & 40.8 \\
Transit & 17.6 & 0.0 & 1.0 & 5.3 & 14.5 & 269.9 & 50.4 & 38.4 \\
School & 10.1 & 0.0 & 1.3 & 3.2 & 11.4 & 137.3 & 40.8 & 27.2 \\
\hline
\end{tabular}

${ }^{a}$ Statistics were computed by exponentiating 1-min averaged logged concentrations, determining the increase amount within subject samples (subject, day and microenvironment), then computing composite statistics across the 125 samples. PM concentrations (micrograms per cubic meter) have been corrected by gravimetric filter mass collected concurrently with each daily pDR sample 
Table 4 Pearson correlations within and between microenvironments for PM exposure metrics (125 records)

\begin{tabular}{|c|c|c|c|c|c|c|c|c|c|c|}
\hline \multirow{2}{*}{$\begin{array}{c}\text { Exposure } \\
\text { Metric }\end{array}$} & & \multicolumn{3}{|c|}{ Mean } & \multicolumn{3}{|c|}{ Increase } & \multicolumn{3}{|c|}{ 1-minute max } \\
\hline & & H & $\mathbf{T}$ & $\mathbf{S}$ & H & $\mathbf{T}$ & $\mathbf{S}$ & H & $\mathbf{T}$ & $\mathbf{S}$ \\
\hline \multirow{3}{*}{ Mean } & H & 1 & & & & & & & & \\
\hline & $\mathbf{T}$ & 0.423 & 1 & & & & & & & \\
\hline & $\mathbf{S}$ & 0.335 & 0.772 & 1 & & & & & & \\
\hline \multirow{3}{*}{ Increase } & H & 0.587 & 0.379 & 0.173 & 1 & & & & & \\
\hline & $\mathbf{T}$ & 0.13 & 0.554 & 0.335 & 0.241 & 1 & & & & \\
\hline & $\mathbf{S}$ & -0.063 & 0.139 & 0.452 & -0.094 & 0.128 & 1 & & & \\
\hline \multirow{3}{*}{$\underset{\max }{1-\operatorname{minute}}$} & H & 0.857 & 0.384 & 0.204 & 0.835 & 0.188 & -0.107 & 1 & & \\
\hline & $\mathbf{T}$ & 0.343 & 0.805 & 0.498 & 0.405 & 0.791 & 0.089 & 0.39 & 1 & \\
\hline & $\mathbf{S}$ & 0.133 & 0.555 & 0.780 & 0.067 & 0.358 & 0.749 & 0.057 & 0.411 & 1 \\
\hline
\end{tabular}

See text for more detail on pollution variable definitions. $\mathrm{H}=$ Home, $\mathrm{T}=$ Transit, $\mathrm{S}=\mathrm{School}$ microenvironments. Pollution variables were considered on the natural log scale (before taking the relevant summary statistic). Correlations exceeding 0.7 are shown in red, and those with $|r|<0.3$ are in blue

results as with mean concentrations (not shown) as these exposure variables were strongly correlated within the same microenvironment $(r>0.75)$.

Urinary cotinine levels were assayed in samples used to measure $\mathrm{uLTE}_{4}$. Urinary cotinine levels were significantly related to same-day $\mathrm{uLTE}_{4}$ levels, but not to albuterol usage in models that did not include PM exposure variables. Adding same-day cotinine levels as a predictor to models with a pollution variable (either mean $\mathrm{PM}_{1.5}$ or an exposure event indicator) generally yielded positive but either marginally significant or insignificant relationships between cotinine and health outcomes (uLTE ${ }_{4}$ and albuterol) for each microenvironment, and the addition of cotinine did not substantially change the pollutant effects on these health outcomes.

\section{Discussion}

Studies of air pollution effects on childhood asthma have classically utilized area-wide monitors as a surrogate for personal exposures $[14,15]$. This approach assumed that exposures were relatively homogenous across the population of concern. However, spatial gradients in air pollution exposures have been demonstrated using both static measurements (i.e., distance to roadway) and locationactivity data across the built environment (e.g., moving from indoors to outdoors) [16-18]. In this context, health effect studies have generally shown greater effects in populations who live closer to air pollution sources and have indirectly suggested (by multivariable regression analysis controlling for other covariates) that this proximity effect was a result of spatially heterogeneous exposures that dissipate as the distance from the source increases [19-21].

In this pilot study we utilized a novel approach to measure spatially and temporally heterogeneous exposures and their potential health effects on children with asthma. In this context, however, we characterized heterogeneity in exposure by quantifying personal exposure in different microenvironments. This approach was enabled by the use of wearable direct-reading sensors (PM, GPS, temperature) with a spatial/temporal algorithm. Furthermore, we analyzed our data using an exposure event variable, in addition to the traditional method of calculating mean exposures. This exposure event metric was defined as a change that begins and ends in the same microenvironment and thus more clearly segregates exposures by microenvironment.

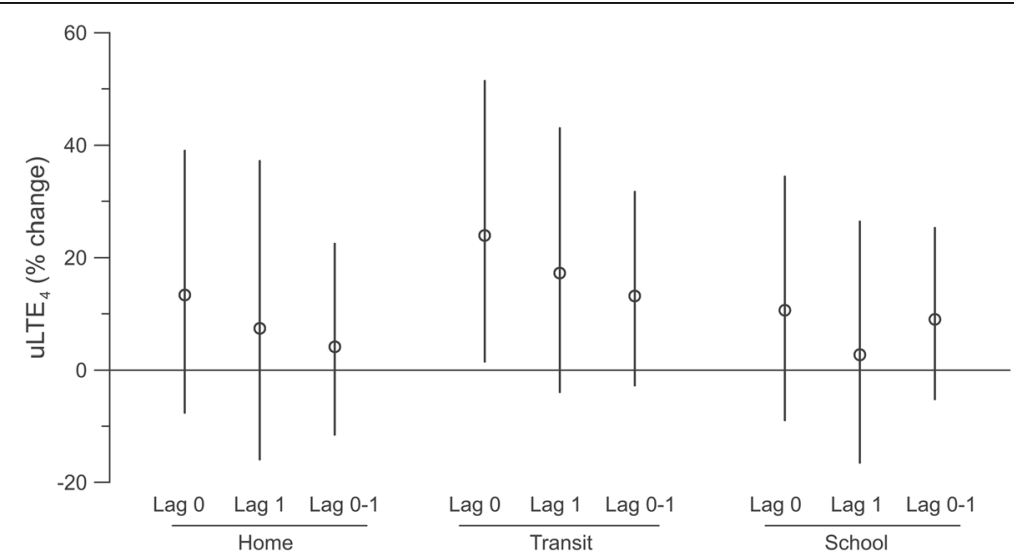

Fig. 2 Associations between $5 \mu \mathrm{g} / \mathrm{m}^{3}$ (or more) exposure events and percent change in $\mathrm{LLTE}_{4}$ within each microenvironment for current day (lag 0), previous day (lag 1) or either day (0-1). Mean estimates are circles and error bars represent $95 \%$ confidence intervals 


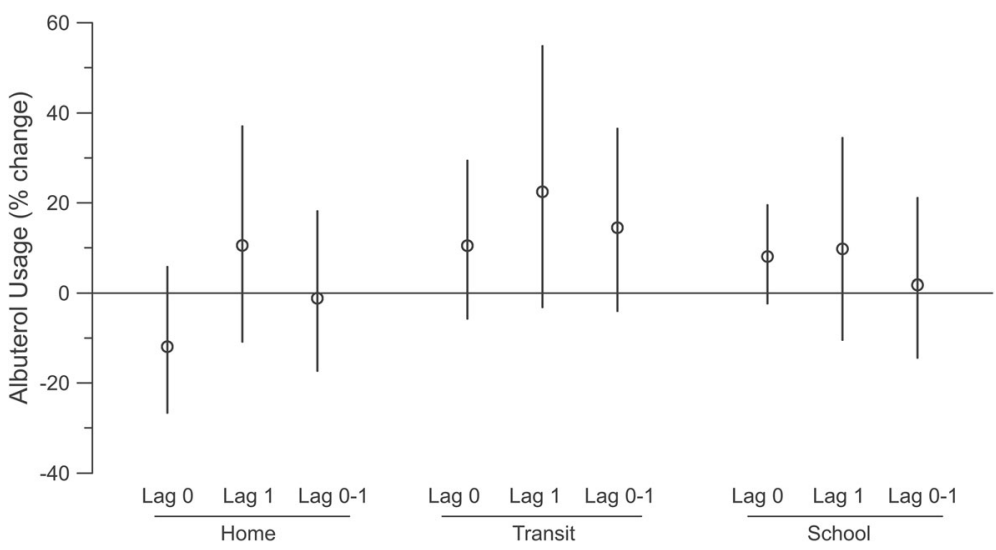

Fig. 3 Associations between $5 \mu \mathrm{g} / \mathrm{m}^{3}$ (or more) exposure events and percent change school time albuterol usage within each microenvironment for current day (lag 0), previous day (lag 1) or either day (0-1). Mean estimates are circles and error bars represent $95 \%$ confidence intervals

Table 5 Associations between health outcomes (uLTE 4 and albuterol usage) and $\mathrm{PM}_{1.5}$ exposure events (increase of at least 5 or $10 \mu \mathrm{g} / \mathrm{m}^{3}$ within microenvironment) as measured by the personal monitor

\begin{tabular}{|c|c|c|c|c|}
\hline \multirow{2}{*}{$\begin{array}{l}\text { Micro- } \\
\text { environment }\end{array}$} & \multirow{2}{*}{$\begin{array}{l}\text { Exposure } \\
\text { event } \\
\text { increase }\end{array}$} & \multirow{2}{*}{$\begin{array}{l}\text { Lag, } \\
\text { days }\end{array}$} & \multicolumn{2}{|c|}{$\%$ Increase for exposure event $(95 \% \mathrm{Cl})$} \\
\hline & & & Albuterol usage & $\mathrm{LTE}_{4}$ \\
\hline \multirow[t]{6}{*}{ Home } & \multirow[t]{3}{*}{$5 \mu \mathrm{g} / \mathrm{m}^{3}$} & 0 & $-1.7(-17.6,17.2)$ & $13.3(-7.6,39.1)$ \\
\hline & & 1 & $11.0(-10.1,37.1)$ & $7.4(-16.0,37.2)$ \\
\hline & & $0-1$ & $-1.2(-17.3,18.0)$ & $4.1(-11.5,22.5)$ \\
\hline & \multirow[t]{3}{*}{$10 \mu \mathrm{g} / \mathrm{m}^{3}$} & 0 & $10.3(-6.5,30.3)$ & $17.7(-4.8,45.6)$ \\
\hline & & 1 & $13.4(-8.3,40.2)$ & $-3.4(-23.4,21.8)$ \\
\hline & & $0-1$ & $7.6(-7.6,25.1)$ & $9.5(-8.5,31.2)$ \\
\hline \multirow[t]{6}{*}{ Transit } & \multirow[t]{3}{*}{$5 \mu \mathrm{g} / \mathrm{m}^{3}$} & 0 & $9.7(-5.9,27.9)$ & $24.0(1.5,51.5)$ \\
\hline & & 1 & $17.6(-6.9,48.6)$ & $17.2(-3.9,43.1)$ \\
\hline & & $0-1$ & $13.7(-4.3,35.2)$ & $13.2(-2.8,31.7)$ \\
\hline & \multirow[t]{3}{*}{$10 \mu \mathrm{g} / \mathrm{m}^{3}$} & 0 & $10.8(-4.2,28.2)$ & $10.9(-10.4,37.2)$ \\
\hline & & 1 & $6.3(-15.5,33.6)$ & $8.7(-12.7,35.2)$ \\
\hline & & $0-1$ & $7.3(-9.5,27.2)$ & $4.7(-10.5,22.4)$ \\
\hline \multirow[t]{6}{*}{ School } & \multirow[t]{3}{*}{$5 \mu \mathrm{g} / \mathrm{m}^{3}$} & 0 & $13.3(-5.7,36.0)$ & $10.6(-9.0,34.4)$ \\
\hline & & 1 & $5.9(-13.2,29.1)$ & $2.7(-16.5,26.4)$ \\
\hline & & $0-1$ & $1.7(-14.6,21.1)$ & $9.0(-5.2,25.4)$ \\
\hline & \multirow[t]{3}{*}{$10 \mu \mathrm{g} / \mathrm{m}^{3}$} & 0 & $12.4(-5.2,33.2)$ & $19.0(-5.3,49.6)$ \\
\hline & & 1 & $3.1(-19.3,31.6)$ & $0.6(-19.8,26.3)$ \\
\hline & & $0-1$ & $4.8(-11.6,24.3)$ & $9.1(-6.0,26.6)$ \\
\hline
\end{tabular}

For 0-1 day lag, the indicator was ' 1 ' if an event occurred on current or previous day, and ' 0 ' otherwise; observations were weighted by the number of records used in the $0-1$ variable ( 1 or 2 days). For Albuterol usage models, temperature and Friday indicator covariates were used; for uLTE 4 models, temperature and cold indicator were used (the lag for cold was set as the same for the air pollution variable). 30 subjects were available for analysis; number of records used for model fits were: 114,80 and 143 for 0,1 and $0-1$ day estimates for albuterol usage, respectively, and 80, 58 and 111 for uLTE For more detail, see the text
In contrast, mean or maximum exposure levels were more strongly correlated across microenvironments, especially across proximal microenvironments such as home-toschool and transit-to-school. Thus, the use of a mean exposure variable may partially reflect spatially homogenous exposures that occur across microenvironments from common sources (i.e., ambient, regional air pollution) or carryovers in exposure from one microenvironment to the next (i.e., the personal cloud effect). As such, the use of a mean exposure variable may be subject to confounding if used to examine health effect associations related to a given microenvironment. For these reasons, the exposure event variable may be better suited for microenvironmental studies of personal exposure/health.

Personal monitoring studies in children with asthma have been previously performed by our group and others using time-integrated approaches $[11,22]$. These studies reported on the impact of measurement error on health effects when area-wide measurements are used as a surrogate for personal exposures to ambient air pollutants. This more traditional approach to personal monitoring (utilizing time-averaged, filter-based measurements integrated over $24 \mathrm{~h}$ ) is useful for determining personal exposures to regional ambient PM concentrations since correlations between personal and central monitor levels strengthen over longer time frames [2, 3]. This integrated personal monitoring approach, however, is less sensitive to spatially or temporally heterogeneous exposures that occur over shorter time periods. These transient changes in exposures may be especially biologically relevant in the context of acute asthma worsening mediated by cysteinyl leukotriene release from mast cells. Cysteinyl leukotrines and other important asthma mediators are stored in preformed granules and released within $15 \mathrm{~min}$ of allergen exposure resulting in acute elevations in $\mathrm{uLTE}_{4}$ levels and early allergen-induced 
bronchoconstriction [23]. Similar to patterns after allergen exposure, maximum morning $\mathrm{PM}_{2.5}$ concentrations were associated with same-day increased uLTE $_{4}$ levels within a few hours of maximum concentrations and dissipated by the following day [24]. This association was attenuated in children previously exposed to second hand smoke on the same day thus suggesting a relatively early homeostatic response that limits further responses to exposure over time [12, 25]. Together these data imply that, continuous exposure and health monitoring might be critical to study acute effects of cysteinyl leukotriene induced asthma worsening and that, in this context, the rate of change in exposure might be more biologically relevant than the absolute level of exposure over a given time period.

Although health effect studies using real-time personal monitoring and/or microenvironmental apportioning have been reported, there are important differences in the present approach compared to previous work. For example, Adar et al. [26] measured microenvironmental exposures for seniors riding on a group bus trip and evaluated associations between $\mathrm{PM}_{2.5}$ exposures and exhaled nitric oxide. These measures were group-wide (area monitoring) and did not account for personal exposure (between-subject). Delfino et al. [27] examined $\mathrm{FEV}_{1}$ exposure using a realtime monitor. Although they reported on exposures by time, they did not report associations by microenvironment (i.e., Delfino et al. tested various time lags from hourly to daily). In addition, they examined peak exposures but not the within-microenvironment increase variable described in the present study. In fact, we are unaware of any research that has used such metrics in the context of microenvironmental exposure and health outcomes.

Although previous research has reported on the health effects of PM exposure by microenvironment, these reports have inherent limitations compared to the approach used in the present study. These limitations include utilizing area-wide measurements [26] to attribute exposures to groups of individuals as they move between various microenvironments and reliance on time-activity diaries to determine exposure by microenvironment [27]. In contrast, the present study has utilized personal exposure monitoring (to capture inter-subject variability in exposure) in conjunction with automated $[4,28]$ microenvironment determination (to reduce participant burden and subject error from timeactivity diaries) across a 24-h monitoring period.

The most important limitation of this study was its small sample size, which occurred primarily due to the increased resources required to perform personal sampling. Although this pilot study was somewhat underpowered to observe statistically significant health effects, the effect estimates suggest that microenvironmentspecific exposures might result in clinically significant effects on asthma as health estimates were generally positive and consistent. Caution should be taken when applying these health effect estimates broadly, due to the relatively wide confidence intervals. Despite the small sample size, some health estimates (especially transit exposures) approached or attained statistical significance. There is also some suggestion that health effects to the same level of PM may vary by microenvironment as health effects were generally strongest for PM exposures occurring while in transit compared to home or school exposures. Such differential estimates might suggest PM sources or exposure patterns with different toxicities in different microenvironments. Unfortunately, because realtime measurement of PM source components were not available when the study was performed, we could not determine sources within microenvironments except for an assessment of the contribution from second hand smoke (via urinary cotinine). Other less substantial study limitations include the fact that some models using the mean metric were influenced strongly by outliers; however, this was not the case for the analyses using the exposure event metric. Although the use of light-scattering for estimating PM mass concentrations is subject to measurement error, $[8,9]$, we attempted to correct for such measurement error by normalizing the daily average mass concentration reported by the pDR to that of a filter sampler (located immediately downstream of the pDR sensing zone).

If confirmed in a larger study, these data would suggest that the amount of time spent in transit versus other microenvironments might be an important determinant of acute asthma worsening. Recent studies have reported that in-vehicle $\mathrm{PM}_{2.5}$ and $\mathrm{NO}_{2}$ concentrations consistently exceeded regional outdoor levels and that each unit increase in the rate of encountering diesel vehicles (count $/ \mathrm{min}$ ) was associated with a more than doubling increase in in-vehicle concentrations of ultrafine particles, black carbon, and $\mathrm{PM}_{2.5}$ as well as substantial increases (>15\%) in indoor/outdoor ratios [29]. Mirabelli et al. recently reported increased exhaled nitric oxide levels in adults with asthma after scripted rushhour commutes [30]. These findings, along with results from the present study, support an examination of transit patterns in for children with persistent asthma and suggest that health improvements may accrue by attenuating transit exposures. In this context, a recent study by Wu et al. [31] demonstrated that the strongest predictors of personal exposure to polycyclic aromatic hydrocarbons in adult women were time spent in vehicles and, to a lesser extent, overall traffic density during transit. If exposure patterns in children are similar to adults, potential recommendations for improving health in children with persistent asthma might include minimizing time in vehicles (especially those with poor filtration systems) and avoiding transit on busy roads. 


\section{Conclusion}

This pilot study has demonstrated, as proof of concept, the utility of spatial-temporal personal exposure monitoring to measure PM exposures as they occurred within three characteristic microenvironments. The potential for clinically significant health effects from spatially/temporally heterogeneous exposures in children with asthma is also suggested although a larger study will be needed to confirm this potentially important relationship.

\section{Additional file}

Additional file 1: Supplementary materials. (PDF 1699 kb)

\section{Abbreviations}

$\mathrm{FEV}_{1}$ : Forced expiratory volume in 1 second; GIS: Geographic information system; GPS: Global positioning system; hr0: Mean log PM 1.5 concentration in the 60 minutes preceding urine collection; hr1: Mean log PM $_{1.5}$ concentration for the 60 minutes ending 1 hour before urine collection; hr2: Mean log PM concentration for the 60 minutes ending 2 hours before urine collection; $\mathrm{NJH}$ : National Jewish Health; $\mathrm{NO}_{2}$ : Nitrogen dioxide; pDR: Personal DataRAM model 1200; PM: Particulate matter; PM1.5: Particulate matter with aerodynamic diameter less than 1.5 microns; ULTE$_{4}$ : Urinary leukotriene E4; URI: Upper respiratory infection

\section{Acknowledgements}

The authors wish to thank Kate Marquart for assisting with data collection and study coordination.

\section{Funding}

Funding for this work was provided in part by the CSU/CVMBS College Research Council and NIH/NIEHS ES015510-01.

\section{Availability of data and materia}

Additional information on the exposure assessment methodology, statitisca models, outcomes by mean exposure, and individual exposure profiles are provided in the Additional file 1. Please contact the authors for additional data requests.

\section{Authors' contributions}

$\mathrm{NR}, \mathrm{CA}, \mathrm{MS}$, and JV conceived of the study and participated in its design and coordination. KK and MS conducted the statistical analyses. All authors helped to draft the manuscript. All authors read and approved the final manuscript.

\section{Competing interests}

The authors declare that they have no competing interests.

\section{Consent for publication}

Not applicable.

\section{Ethics approval and consent to participate}

Ethical and scientific approval for this work was obtained from the NJH Institutional Review Board.

\footnotetext{
Author details

${ }^{1}$ Department of Pediatrics, National Jewish Health, Denver, CO, USA. ${ }^{2}$ Department of Environmental and Radiological Health Sciences, Colorado State University, Fort Collins, CO, USA. ${ }^{3}$ Division of Biostatistics and Bioinformatics, National Jewish Health, Denver, CO, USA. ${ }^{4}$ Department of Environmental Health Sciences, Johns Hopkins University, Baltimore, MA, USA. ${ }^{5}$ Department of Mechanical Engineering, Colorado State University, 1374 Campus Delivery, Fort Collins, CO 80523, USA.
}

Received: 28 October 2015 Accepted: 28 September 2016 Published online: 10 October 2016

\section{References}

1. Mann JK, Balmes JR, Bruckner TA, Mortimer KM, Margolis HG, Pratt B, Hammond SK, Lurmann FW, Tager IB. Short-term effects of air pollution on wheeze in asthmatic children in Fresno, California. Environ Health Perspect. 2010;118:1497-502.

2. Strand M, Hopke PK, Zhao W, Vedal S, Gelfand E, Rabinovitch N. A study of health effect estimates using competing methods to model personal exposures to ambient PM2.5. J Expo Sci Environ Epidemiol. 2007;17:549-58.

3. Hutcheon J. Random measurement error and regression dilution bias. BMJ. 2010:341:1402.

4. Adams C, Riggs P, Volckens J. Development of a method for personal, spatiotemporal exposure assessment. J Environ Monit. 2009;11:1331-9.

5. Quintana PJE, Samimi BS, Kleinman MT, Liu LJ, Soto K, Warner GY, Bufalino C, Valencia J, Francis D, Hovell MH, Delfino RJ. Evaluation of a real-time passive personal particle monitor in fixed site residential indoor and ambient measurements. J Expos Sci Environ Epidemiol. 2000;10:437-45.

6. Howard-Reed C, Rea AW, Zufall MJ, Burke JM, Williams RW, Suggs JC, Sheldon LS, Walsh D, Kwok R. Use of a continuous nephelometer to measure personal exposure to particles during the US Environmental Protection Agency Baltimore and Fresno panel studies. J Air Waste Manage Assoc. 2000:50:1125-32.

7. Fischer SL, Koshland CP. Field performance of a nephelometer in rural kitchens: effects of high humidity excursions and correlations to gravimetric analyses. J Expo Sci Environ Epidemiol. 2007;17:141-50.

8. Chakrabarti B, Fine PM, Delfino R, Sioutas C. Performance evaluation of the active-flow personal DataRAM PM 2.5 mass monitor (Thermo Anderson pDR-1200) designed for continuous personal exposure measurements. Atmos Environ. 2004:38:3329-40.

9. Benton-Vitz K, Volckens J. Evaluation of the pDR-1200 real-time aerosol monitor. J Occup Environ Hyg. 2008:5:353-9.

10. Armstrong M, Liu AH, Harbeck R, Reisdorph R, Rabinovitch N, Reisdorph N. Leukotriene E4 in human urine: Comparison of on-line purification and liquid chromatography-tandem mass spectrometry to affinity purification followed by enzyme immunoassay. J Chromatogr B. 2009;877:3169-74.

11. Rabinovitch N, Strand M, Gelfand EW. Particulate levels are associated with early asthma worsening in children with persistent disease. Am J Respir Crit Care Med. 2006;173:1098-105.

12. Rabinovitch N, Silveira L, Gelfand EW, Strand M. The response of children with asthma to ambient particulate is modified by tobacco smoke exposure. Am J Respir Crit Care Med. 2011;184:1350-7.

13. Busse WW, Lemanske RF. Expert Panel Report 3: Moving forward to improve asthma care. J Allergy Clin Immunol. 2007;120:1012-4.

14. Strickland MJ, Darrow LA, Klein M, Flanders WD, Sarnat JA, Waller LA, Sarnat SE, Mulholland JA, Tolbert PE. Short-term associations between ambient air pollutants and pediatric asthma emergency department visits. Am J Respir Crit Care Med. 2010;182:307-16

15. Silverman RA, Ito K. Age-related association of fine particles and ozone with severe acute asthma in New York City. J Allergy Clin Immunol. 2010;125:367-73.

16. Kim J, Smorodinsky S, Lipsett M, Singer B, Hodgson A, Ostro B. Traffic-related air pollution near busy roads - The East Bay children's respiratory health study. Am J Respir Crit Care Med. 2004;170:520-6.

17. Steinle S, Reis S, Sabel CE. Quantifying human exposure to air pollution-Moving from static monitoring to spatio-temporally resolved personal exposure assessment. Sci Total Environ. 2013;443:184-93.

18. Karner AA, Eisinger DS, Niemeier DA. Near-roadway air quality: synthesizing the findings from real-world data. Environ Sci Technol. 2010;44:5334-44.

19. Pénard-Morand C, Raherison C, Charpin D, Kopferschmitt C, Lavaud F, Caillaud D. Annesi-Maesano I. Long-term exposure to close-proximity air pollution and asthma and allergies in urban children. Eur Respir J. 2010;36:33-40.

20. McConnell R, Islam T, Shankardass K, Jerrett M, Lurmann F, Gilliland F, Gauderman J, Avol E, Künzli N, Yao L. Childhood incident asthma and traffic-related air pollution at home and school. Environ Health Perspect. 2010;1021-1026.

21. Nordling E, Berglind N, Melen E, Emenius G, Hallberg J, Nyberg F, Pershagen G, Svartengren M, Wickman M, Bellander T. Traffic-related air pollution and childhood respiratory symptoms, function and allergies. Epidemiology. 2008;19:401.

22. Delfino RJ, Staimer N, Tjoa T, Gillen D, Kleinman MT, Sioutas C, Cooper D. Personal and ambient air pollution exposures and lung function decrements in children with asthma. Environ Health Perspect. 2008;116:550-8.

23. Bancalari L, Conti I, Giannessi D, Lazzerini G, Dente FL, De Caterina R, Paggiaro PL. Early increase in urinary Leukotriene $\mathrm{E} 4\left(\mathrm{LTE}_{4}\right)$ is dependent on 
allergen dose inhaled during bronchial challenge in asthmatic subjects. Allergy. 1999;54:1278-85.

24. Rabinovitch N, Zhang L, Gelfand EW. Urine leukotriene E4 levels are associated with decreased pulmonary function in children with persistent airway obstruction. J Allergy Clin Immunol. 2006;118:635-40.

25. Baccarelli A, Kaufman JD. Ambient particulate air pollution, environmental tobacco smoking, and childhood asthma: interactions and biological mechanisms. Am J Respir Crit Care Med. 2011;184:1325-7.

26. Adar SD, Adamkiewicz G, Gold DR, Schwartz J, Coull BA, Suh H. Ambient and microenvironmental particles and exhaled nitric oxide before and after a group bus trip. Environ Health Perspect. 2007;115:507-12.

27. Delfino RJ, Quintana PJ, Floro J, Gastañaga VM, Samimi BS, Kleinman MT, Liu LS, Bufalino C, Wu C-F, McLaren CE. Association of FEV1 in asthmatic children with personal and microenvironmental exposure to airborne particulate matter. Environ Health Perspect. 2004:112:932.

28. Nethery E, Mallach G, Rainham D, Goldberg MS, Wheeler AJ. Using Global Positioning Systems (GPS) and temperature data to generate time-activity classifications for estimating personal exposure in air monitoring studies: an automated method. Environ Health. 2014;13:1.

29. Weichenthal S, Van Ryswyk K, Kulka R, Sun L, Wallace L, Joseph L. In-vehicle exposures to particulate air pollution in canadian metropolitan areas: The urban transportation exposure study. Environ Sci Technol. 2014:49:597-605.

30. Mirabelli MC, Golan R, Greenwald R, Raysoni AU, Holguin F, Kewada P, Winquist A, Flanders WD, Sarnat JA. Modification of traffic-related respiratory response by asthma control in a population of car commuters. Epidemiology. 2015;26:546-55.

31. Wu J, Tjoa T, Li L, Jaimes G, Delfino RJ. Modeling personal particle-bound polycyclic aromatic hydrocarbon (pb-pah) exposure in human subjects in Southern California. Environ Health. 2012;11:47.

\section{Submit your next manuscript to BioMed Central and we will help you at every step:}

- We accept pre-submission inquiries

- Our selector tool helps you to find the most relevant journal

- We provide round the clock customer support

- Convenient online submission

- Thorough peer review

- Inclusion in PubMed and all major indexing services

- Maximum visibility for your research

Submit your manuscript at www.biomedcentral.com/submit

) Biomed Central 